\title{
Risk of infections transmitted by arthropods and rodents in forestry workers
}

\author{
A.W. Moll van Charante ${ }^{1}$, J. Groen ${ }^{2}$ \& A.D.M.E. Osterhaus ${ }^{3}$ \\ ${ }^{1}$ State Occupational Health Service, RBB, P.O.Box 20012, 2500 EA The Hague, The Netherlands; ${ }^{2}$ Department of \\ Clinical Virology University Hospital, Rotterdam, The Netherlands; ${ }^{3}$ Institute of Virology Erasmus University, \\ Rotterdam, The Netherlands
}

Accepted in revised form 31 May 1994

\begin{abstract}
One hundred and fifty-one forestry workers and 151 matched office clerks were compared as to the presence of antibodies against Borrelia burgdorferi, tick-borne encephalitis virus, Puumalavirus and lymphocytic choriomeningitis virus. Their occupational risks of being infected by
\end{abstract}

Borrelia was fourfold and significant, by Puumalavirus and lymphocytic choriomeningitis virus was increased but not significant. No seropositivity has been established against tick-borne encephalitis virus.

Key words: Forestry workers, Hantavirus nephropathy, Lyme borreliosis, Lymphocytic choriomeningitis, Occupational risk, Tick-borne encephalitis

The medical community is becoming increasingly interested in infectious diseases which are difficult to detect by ordinary clinical investigation, such as tick-borne encephalitis (TBE), haemorrhagic fever with renal syndrome (HFRS), and lymphocytic choriomeningitis (LCM), or which incidentally are difficult to distinguish from other clinical entities, such as lyme borreliosis (LB). Recent studies indicate that these four diseases are widely distributed throughout the world [1-5]. In fact they are the most important infectious diseases transmitted to humans by arthropods and rodents in the forested areas in Western Europe.

LB, a spirochetosis caused by Borrelia burgdorferi, is tick-borne with small rodents as reservoir - as is TBE, which is caused by a member of the Flaviviridae family $[6,7]$. In Europe both are mostly transmitted through bites by ticks (Ixodes ricinus).

HFRS, caused by the Puumalavirus (PUUV) of the genus Hantavirus, a member of the Bunyaviridae family [8, 9], and LCM, which is caused by lymphocytic choriomeningitis virus, a member of the Arenaviridae family are transmitted through direct or indirect contacts wild rodents [10].

Individuals who are professionally involved in forestry work and those who live in forested areas may be expected to be at increased risk of acquiring these infections. A number of studies have been devoted to such populations [11-14]. However, they lacked the use of a matched control group. Therefore, we report here on the comparison of a sample of forestry workers with a matched control group with regard to the prevalence of seropositivity against these four infectious diseases.

Dutch forestry workers employed in the maintenance of state-owned woodland, heathland and national parks are public employees. This population $(n=750)$ receives occupational medical care from the State Occupational Health Service. A cohort of 151 of these forestry workers, employed at six of the 23 forestry stations (20\%), were screened for markers of these infectious diseases in April 1989 and April 1990. The first screening also included a control group of office clerks, also civil servants categorically matched to the 151 participating forestry workers by age (same decennium) and occupational health centre as a proxy variable for area of domicile.

Serum samples were stored after collection at $-20{ }^{\circ} \mathrm{C}$ until use. The commercially available flagellum enzyme-linked immunosorbent assay (ELISA) (K416, Dakopatts, Glostrup, Denmark) was used for the detection of $\mathrm{IgG}$ directed against Borrelia burgdorferi and used as described by the manufacturer. Sera with optical density (OD) value above the cutoff of 0.40 were considered positive after confirmation by Western blot $[15,16]$.

TBEV-specific antibodies were measured using the commercially available indirect FSME ELISA (Virotech, Heidelberg, Germany).

For the detection of Hantavirus-specific IgG antibodies the indirect ELISA was used as described elsewhere [9]. Hantavirus-positive ELISA reactions were captured by indirect immunofluoresence assay (IFA).

LCMV-specific antibodies were measured by 


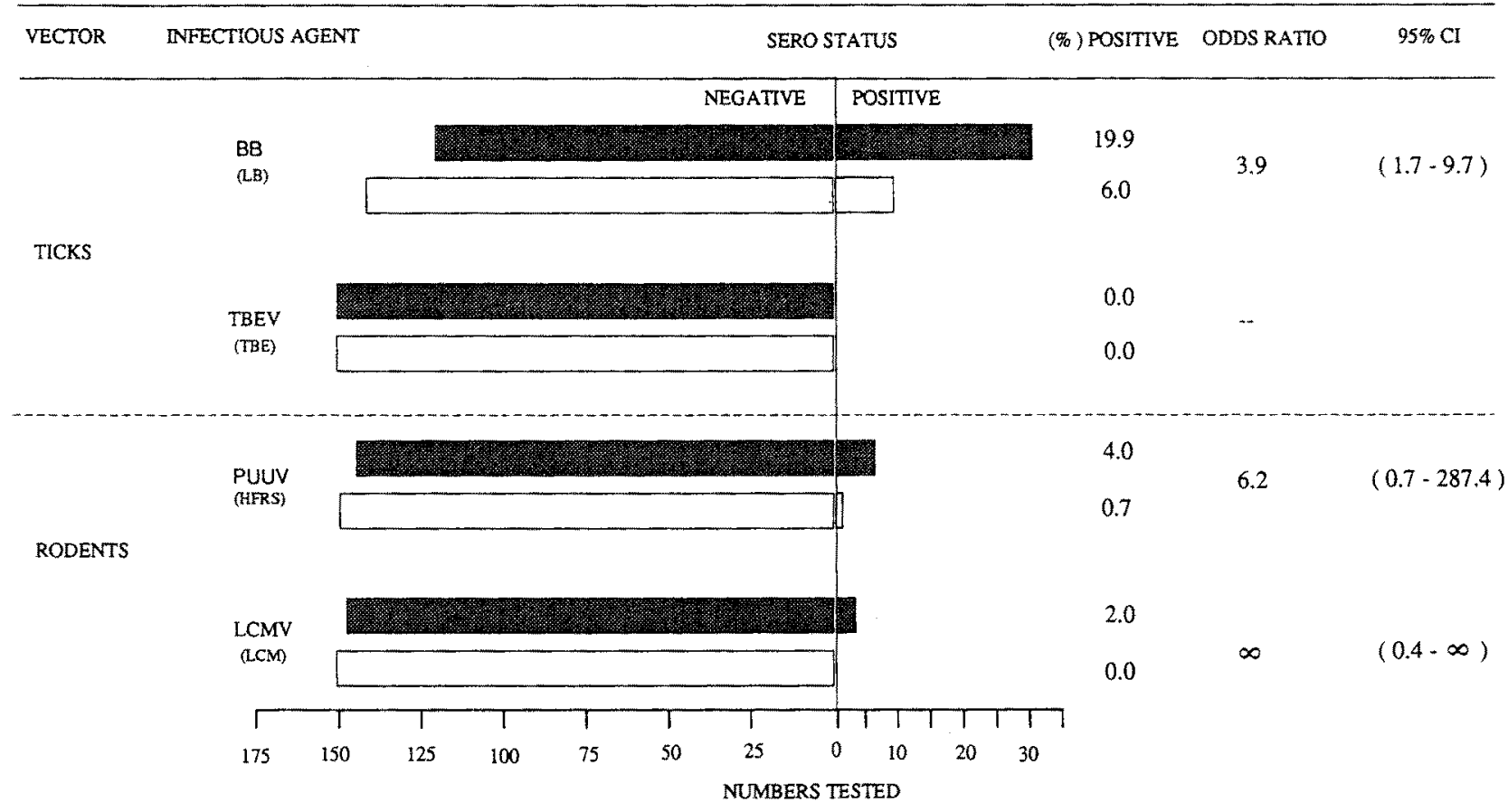

Figure 1. Seroprevalence of arthropod and rodent transmitted infections in forestry workers in the Netherlands.

forestry workers; $\square$ non-forestry workers.

indirect ELISA. The viral and control antigen were prepared from ATCC VR134 virus-infected and uninfected BHK cells. Five days after infection medium was removed and the cells were washed with phosphate buffered saline, $\mathrm{pH} 7.2$ (PBS), trypsinised, washed with PBS plus $10 \%$ FCS and centrifuged for $5 \mathrm{~min}$ at $580 \mathrm{~g}$. The cell pellet was resuspended in $1 \mathrm{ml}$ PBS and sonicated twice for 15 seconds. Cellular debris was removed by low-speed centrifugation. The supernatant was inactivated with $1 \%$ ethylene oxide and used as antigen after storage at $-70{ }^{\circ} \mathrm{C}$. The LCM virus IgG-ELISA was performed as described for Hantavirus-specific antibodies [8]. The indirect IFA was used to confirm the OD values higher than 0.2 above the control antigen level, using drop slides with LCM virus-infected and uninfected BHK cells fixed with $70 \%$ ethanol and stored at $-70^{\circ} \mathrm{C}$ until use.

The results of the screening for tick-transmitted infections show that $30(19.9 \%)$ of the forestry workers versus nine $(6.0 \%)$ of the clerks (odds ratio 3.9 , exact estimation) had serum antibodies to Borrelia burgdorferi [17], a statistically significant difference, whereas no serum antibodies against TBE were found in either group (Fig. 1). The results of the screening for serum antibodies to the viruses transmitted through contacts with rodents show that six $(4.0 \%)$ forestry workers had serum antibodies to PUUV versus one $(0.7 \%)$ of the clerks. It is interesting to note that four of the PUUV-seropositive individuals worked in areas where 14 clinical cases of HFRS had been diagnosed before $[8,18]$. Three $(2.0 \%)$ forestry workers had serum antibiotics to LCMV versus none $(0.0 \%)$ of the clerks.
A hundred and fifty-one forestry workers were sampled for the second time in April 1990. Five of them, who had no serum antibodies to LB in 1989 , were seropositive in 1990 [18]. None of these five individuals had developed clinical symptoms suggestive of LB during the period between the two samplings $[17,19]$. No seroconversions towards TBE, PUUV and LCMV were found in the 151 individuals.

Taken together, our data suggest that forestry workers in The Netherlands have an increased risk of LB. Their occupational hazards to PUUV and LCMV infections however, remain to be corroborated.

\section{References}

1. Editorial. Infectious dieases are not banished. Nature 1992; $359: 657-658$.

2. Rahn WR, Malawista SE. Lyme disease: recommendations for diagnosis and treatment. Ann Int Med 1991; 114: 472-481.

3. Holmgren EB, Forsgren M. Epidemiology of tickborne encephalitis in Sweden 1956-1989: a study of 1116 cases. Scand J Inf Dis 1990; 22: 287-295.

4. Groen J, Osterhaus ADME, Avsic-Zupanc T. Different hantavirus serotypes in Western Europe. The Lancet 1991 (i): 621-622.

5. Nuti M, Amaddeo D, Crovatto M, Ghionni A, Polato D, Lillini E, Pitzus A, Santini GF. Infections in an alpine environment: antibodies to Hantaviruses, Leptospira, Rickettsiae, and Borrelia burgdorferi in defined Italian populations. Am J Trop Med Hyg 1993; 48: 20-25.

6. Schwartz BS, Goldstein MD. Lyme disease in outdoor workers: risk factors, preventive measures, and tick 
removal methods. Am J Epidemiol 1990; 131: 877-885.

7. World Health Organisation. Tick-borne encephalitis and hemorrhagic fever with renal syndrome in Europe. EURO Reports and Studies 1986; 104: 1-15.

8. Osterhaus ADME, Groen J. Hantavirus nephropathy in the Netherlands. Lancet 1989 (ii): 338-339.

9. Groen J, Jordans HGM, Clement JPG, Rooijakkers EJ, UytdeHaag FGCM. Identification of Hantavirus serotypes by testing post-infection sera in immunoflorescence and enzyme-linked immunosorbent assay. J Med Virol 1991; 33: 26-32.

10. Childs JE, Glass GE, Korch GW, Ksiazek TG, Leduc JW. Lymphocytic choriomeningitis infection of house mouse (mus musculus) distribution in Urban Baltimore. Am J Trop Med Hyg 1992; 1: 27-34.

11. Stanford CF, Conolly JH, Ellis WA. Zoonotic infections in Northern Ireland Farmers. Epidemiol Infect 1990; 105: 565-571.

12. Guy E, Martyn CN, Bateman DE, Heckels JE, Lawton NF. Lyme disease: Prevalence and clinical importance of Borrelia burgdorferi-specific IgG in forestry workers. Lancet 1989 (i): 484-485.

13. Niklasson B, Jonsson M, Widegren I. A study of nepfropathia epidemica among military personnel in Sweden. Res Virol 1992; 143: 211-214.

14. Clement JP, Leirs H, Armoun V. Serological evidence for Tick-borne encephalitis (TBE) in North-American military personnel stationed in Germany. Proc. of Third Internat. Symp. on Arbovirus and Hantavirus in
Mediterranean Countries. Cortina d'Ampezzo, Italy 25-29 March 1992.

15. Ma B, Christen B, Leung D, Vigo-Perlfrey $C$. Serodiagnosis of Lyme borreliosis by Western immunoblot: reactivity of various significant antibodies against Borrelia burgdorferi. J Clin Microbiol 1992; 30: 370-376.

16. Hansen K, Asbrink E. Serodiagnosis of erythema migrans and acrodermatitis chronica atrophicans by Borrelia burgdorferi flagellum enzyme-linked immunosorbent assay. J Clin Microbiol 1989; 27 : 545-551.

17. Moll van Charante AW, Nauta AP, Kuiper $H$. The occupational risk of Lyme borreliosis. Tijdschr Toegep Arbowetenschap 1992; 5: 60-67 (in Dutch).

18. Schmutzhard E, Stanek G, Pletschette M, Hirschl AM, Pallua A, Schmitzberger R, Schloegl R. Infections following tick bites: Tick-borne encephalitis and Lyme borreliosis, a prospective epidemiological study from Tyrol. Infection 1988; 16: 269-271.

19. Jordans JMG, Groen J, Lefevre A, Clement J, Haraldsdòttir V, Osterhaus ADME. Hanta-infections in Twente. Ned Tijdschr Geneesk 1991; 18: 796-798 (in Dutch).

Address for correspondence: A.W. Moll van Charante, State Occupational Health Service, RBB, P.O.Box 20012, 2500 EA The Hague, The Netherlands

Phone: (70) 3767450 